\title{
Photolysis-induced scrambling of PAHs as a mechanism for deuterium storage
}

\author{
Sandra D. Wiersma ${ }^{1,2}$, Alessandra Candian ${ }^{1,3}$, Joost M. Bakker ${ }^{2}$, Jonathan Martens ${ }^{2}$, Giel Berden ${ }^{2}$, Jos Oomens ${ }^{1,2}$, \\ Wybren Jan Buma ${ }^{1,2}$, and Annemieke Petrignani ${ }^{1}$ \\ 1 Van 't Hoff Institute for Molecular Sciences, University of Amsterdam, Science Park 904, 1098 XH Amsterdam, The Netherlands \\ e-mail: s.d.wiersma@uva.nl; a.petrignani@uva.nl \\ 2 Radboud University, Institute for Molecules and Materials, FELIX Laboratory, Toernooiveld 7, 6525 ED Nijmegen, \\ The Netherlands \\ 3 Leiden Observatory, Leiden University, Niels Bohrweg 2, 2300 RA Leiden, The Netherlands
}

Received 23 October 2019 / Accepted 9 January 2020

\begin{abstract}
Aims. We investigate the possible role of polycyclic aromatic hydrocarbons (PAHs) as a sink for deuterium in the interstellar medium (ISM) and study UV photolysis as a potential underlying chemical process in the variations of the deuterium fractionation in the ISM. Methods. The UV photo-induced fragmentation of various isotopologs of deuterium-enriched, protonated anthracene and phenanthrene ions (both $\mathrm{C}_{14} \mathrm{H}_{10}$ isomers) was recorded in a Fourier Transform Ion Cyclotron Resonance Mass Spectrometer. Infrared multiple photon dissociation spectroscopy using the Free-Electron Laser for Infrared eXperiments was applied to provide IR spectra. Infrared spectra calculated using density functional theory were compared to the experimental data to identify the isomers present in the experiment. Transition-state energies and reaction rates were also calculated and related to the experimentally observed fragmentation product abundances.

Results. The photofragmentation mass spectra for both UV and IRMPD photolysis only show the loss of atomic hydrogen from $\left[D-\mathrm{C}_{14} \mathrm{H}_{10}\right]^{+}$, whereas $\left[\mathrm{H}-\mathrm{C}_{14} \mathrm{D}_{10}\right]^{+}$shows a strong preference for the elimination of deuterium. Transition state calculations reveal facile 1,2-H and -D shift reactions, with associated energy barriers lower than the energy supplied by the photo-excitation process. Together with confirmation of the ground-state structures via the IR spectra, we determined that the photolytic processes of the two different PAHs are largely governed by scrambling where the $\mathrm{H}$ and the $\mathrm{D}$ atoms relocate between different peripheral $\mathrm{C}$ atoms. The $\sim 0.1 \mathrm{eV}$ difference in zero-point energy between $\mathrm{C}-\mathrm{H}$ and $\mathrm{C}-\mathrm{D}$ bonds ultimately leads to faster $\mathrm{H}$ scrambling than $\mathrm{D}$ scrambling, and increased $\mathrm{H}$ atom loss compared to $\mathrm{D}$ atom loss.

Conclusions. We conclude that scrambling is common in PAH cations under UV radiation. Upon photoexcitation of deuteriumenriched PAHs, the scrambling results in a higher probability for the aliphatic D atom to migrate to a strongly bound aromatic site, protecting it from elimination. We speculate that this could lead to increased deuteration as a PAH moves towards more exposed interstellar environments. Also, large, compact PAHs with an aliphatic C-HD group on solo sites might be responsible for the majority of aliphatic C-D stretching bands seen in astronomical spectra. An accurate photochemical model of PAHs that considers deuterium scrambling is needed to study this further.
\end{abstract}

Key words. astrochemistry - molecular processes - ISM: molecules - infrared: ISM - techniques: spectroscopic methods: laboratory: molecular

\section{Introduction}

Nearly all deuterium in our Universe was formed during the nucleosynthesis era after the Big Bang (Liddle 2003). Since then, it has mostly been depleted through stellar nucleosynthesis leading to variations in its interstellar abundance (Epstein et al. 1976; Reeves et al. 1973). The dispersion in deuterium abundance shows strong ties to the so-called metallicity of the environment, that is, the abundance of elements other than $\mathrm{H}$ and He. However, not all of the dispersion can be attributed to nucleosynthesis. The missing deuterium is likely chemically stored in molecules and grains, making the local interstellar deuterium abundance a direct tracer of chemical activity (Linsky et al. 2006; Draine et al. 2006; Roueff et al. 2007).

A family of molecules in which the missing interstellar deuterium could be stored is that of the polycyclic aromatic hydrocarbons (PAHs; Peeters et al. 2004; Hudgins et al. 2004; Draine et al. 2006; Onaka et al. 2014; Buragohain et al. 2015, 2016; Doney et al. 2016). It has been estimated that about $85 \%$ of the carbon in dust is aromatic (Pendleton \& Allamandola
2002), and that PAHs bear about 5-10\% of all cosmic carbon (Tielens 2013). Their large heat capacity and stable aromatic nature allow them to withstand harsh radiative conditions, and survive by re-emitting the absorbed radiation in well-defined IR spectral regions widely known as the aromatic infrared bands (AIBs). The AIBs are commonly associated with aromatic $\mathrm{C}-\mathrm{C}$ and $\mathrm{C}-\mathrm{H}$ vibrations, and are observed throughout the interstellar medium (ISM) in the 3-18 $\mu \mathrm{m}$ spectral range (Tielens 2008 , 2013; Peeters 2011). Bands in this range are observed in different types of interstellar sources, showing PAHs to be present under different conditions (Ricca et al. 2011; Tielens 2013). Although the AIBs show that aromatic species exist in space, no individual PAH has been identified to date. The only aromatic molecules that have been firmly identified are the possible PAH precursors benzene (Cernicharo et al. 2001; Kraemer et al. 2006) and benzonitrile (McGuire et al. 2018), and the fullerenes $\mathrm{C}_{60}$ and $\mathrm{C}_{70}$ (Cami et al. 2010; Sellgren et al. 2010; Berné et al. 2013; Campbell et al. 2015; Cordiner et al. 2019); the latter two could be formed by the radiative processing of larger PAHs 
(Berné \& Tielens 2012). The ubiquitous presence of interstellar PAHs is further supported by the identification of several PAHs in the Murchison and Allende carbonaceous chondrites. ${ }^{13} \mathrm{C} /{ }^{12} \mathrm{C}$ isotopic studies confirm the interstellar origin of the PAHs on these chondrites (Kerridge et al. 1987; Spencer et al. 2008).

The presence of deuterated PAH species in the ISM is revealed through the observation of $\mathrm{C}-\mathrm{D}$ vibrational bands the aromatic C-D stretch at $4.40 \mu \mathrm{m}$ and the antisymmetric/symmetric aliphatic C-D stretch at $4.63 / 4.75 \mu \mathrm{m}$, respectively (Hudgins et al. 2004; Buragohain et al. 2015, 2016). These bands are detected in regions where the elemental $\mathrm{D}$ abundance is typically lower than expected (Peeters et al. 2004; Draine et al. 2006; Linsky et al. 2006; Onaka et al. 2014) which suggests that PAHs could be acting as a sink for deuterium. However, there is insufficient data on both the observational and experimental side for a reliable analysis of the amount of deuterium contained in gasphase PAHs. Large observational studies are hindered by telluric absorptions in the 4-5 $\mu \mathrm{m}$ range and by the relative weakness of C-D bands (Peeters et al. 2004; Onaka et al. 2014; Doney et al. 2016). Experimental studies are limited to perdeuterated PAHs, known as PADs (Bauschlicher et al. 1997; Hudgins et al. 1994; Piest et al. 2001). Several processes have been suggested to play a role in interstellar D enrichment of PAHs, varying from gasgrain reactions to gas-phase photodissociation (Sandford et al. 2001). Studies on the contributions and role of these mechanisms have largely focused on solid-state processes, that is, on ices and grains.

We report on gas-phase unimolecular photodissociation as a possible driver of interstellar D-enrichment of PAHs. We present the photofragmentation mass spectra for UV photolysis of D-enriched protonated anthracene and phenanthrene. We also present their IR-induced fragmentation mass spectra and infrared spectra using infrared multiple-photon dissociation (IRMPD) spectroscopy. We put forward a possible photolysisinduced mechanism and suggest its role in D-enrichment.

Furthermore, we discuss the astronomical implications of the found mechanism on observations of band intensity ratios for aliphatic and aromatic $\mathrm{C}-\mathrm{H} / \mathrm{C}-\mathrm{D}$ stretch vibrations in PAHs.

\section{Methods}

\subsection{Experimental methods}

The UV photodissociation mass spectra of protonated ([H- $\mathrm{C}_{14}$ $\left.\mathrm{H}_{10}\right]^{+}$), deuteronated $\left(\left[\mathrm{D}-\mathrm{C}_{14} \mathrm{H}_{10}\right]^{+}\right)$, and protonated, perdeuterated $\left(\left[\mathrm{H}-\mathrm{C}_{14} \mathrm{D}_{10}\right]^{+}\right)$anthracene and phenanthrene were recorded using a Fourier Transform Ion Cyclotron Resonance mass spectrometer (FTICR MS) coupled to a Nd:YAG laser. We applied IRMPD spectroscopy using the Free-Electron Laser for Infrared eXperiments (FELIX) also coupled to the FTICR MS. (Oepts et al. 1995; Valle et al. 2005). Both fragmentation mass spectra and infrared spectral signatures are provided by IRMPD. This allows for the determination of the molecular structure of the precursor ions. Moreover, as the fragmentation energies of protonated PAHs are significantly lower than those of PAH radical cations, the IR fragmentation mass spectra of protonated PAHs - unlike their UV counterparts - are exempt from background signal originating from the isobaric ${ }^{13} \mathrm{C}$ radical cation isotopolog. This isotopolog is present in a natural abundance of $15.3 \%$, and cannot be selectively removed according to its mass because of limitations in the mass resolution of our FTICR MS (the ${ }^{12} \mathrm{CH}$ vs. ${ }^{13} \mathrm{C}$ mass difference is $0.0045 \mathrm{amu}$ ).

Anthracene and phenanthrene (Sigma Aldrich Co. LLC.; purity $>98 \%$ ) were dissolved in methanol at $1 \mathrm{mM}$ concen- tration, and brought into the gas-phase via electro-spray ionization (ESI) in a Micromass/Waters Z-spray source. Instead of the typically used ammonium acetate or acetic acid, we used (D-)trifluoroacetic acid, an efficient protonation agent. The advantage of using D-trifluoroacetic acid in deuterated methanol $\left(\mathrm{CH}_{3} \mathrm{OD}\right.$ or $\left.\mathrm{CD}_{3} \mathrm{OD}\right)$ is that ${ }^{1} \mathrm{H}$ contamination is prevented in the deuteronation process; we experimentally found that such contamination does take place with the use of a weak acid such as ammonium acetate (Knorke et al. 2009, in water).

Photolysis experiments on the anthracene and phenanthrene ions were performed in the following sequence. The electrosprayed ions were accumulated in a radio-frequency (RF) hexapole trap. They were then pulse-extracted and transported into the ICR cell via a quadrupole bender and a $1 \mathrm{~m} \mathrm{RF}$ octopole ion guide. The ICR cell was at room temperature and at a pressure of approximately $10^{-8}$ mbar. The precursor ions were massisolated by expelling unwanted masses using a Stored Waveform Inverse Fourier Transform (SWIFT) pulse (Marshall et al. 1985). These ions were then either irradiated in one pass of the UV laser, or with multiple passes of the IR laser beam in a multi-pass configuration, after which all precursor and fragment ions were mass-analyzed. This sequence was repeated three to five times for each wavelength step with a storage and irradiation time of between 2 and $8 \mathrm{~s}$.

For the UV photolysis experiment, the fourth harmonic of the Nd:YAG laser at $266 \mathrm{~nm}$ (4.6611 eV per photon) was used at a pulse energy of $\sim 1 \mathrm{~mJ}$, operated at $10 \mathrm{~Hz}$. For the IRMPD experiment, FELIX was operated at a repetition rate of $10 \mathrm{~Hz}$ using macropulses of $5 \mu \mathrm{s}$. The frequency range covered 700 $1800 \mathrm{~cm}^{-1}(\sim 14-5.5 \mu \mathrm{m})$. The energy per macropulse had a maximum of roughly $65 \mathrm{~mJ}$, and decreased to around $20 \mathrm{~mJ}$ at the $1800 \mathrm{~cm}^{-1}(5.5 \mu \mathrm{m})$ edge of the spectral range studied. The spectral bandwidth (FWHM) of FELIX was set to $\sim 0.5 \%$ of the central frequency, which translates into $5 \mathrm{~cm}^{-1}$ at $1000 \mathrm{~cm}^{-1}$ $(10 \mu \mathrm{m})$. A grating spectrometer with an accuracy of $\pm 0.01 \mu \mathrm{m}$ was used to calibrate the laser wavelength. The laser frequency was changed in steps of $5 \mathrm{~cm}^{-1}$. For measurements focusing on the weaker IR modes, the ions were additionally irradiated for $40 \mathrm{~ms}$ with the output of a $30 \mathrm{~W} \mathrm{cw} \mathrm{CO}$ laser directly after each FELIX pulse in order to enhance the on-resonance dissociation yield (Settle \& Rizzo 1992; Almasian et al. 2012).

\subsection{Theoretical methods}

Density functional theory (DFT) calculations presented in this work were all performed using the Gaussian 09 package (Frisch et al. 2009). The B3LYP functional (Becke 1993; Lee et al. 1988) was used with the $6-311++\mathrm{G}(2 \mathrm{~d}, \mathrm{p})$ basis set to optimize the molecular structure and evaluate the vibrational spectra of the molecules within the harmonic oscillator approximation. B3LYP has been shown previously to accurately predict the vibrational spectra of PAHs (Bauschlicher \& Ricca 2010). A scaling factor of 0.966 was applied to the calculated frequencies, allowing the harmonic calculations to line up with the intrinsically anharmonic measured spectra. The theoretical stick spectra were convoluted with a Gaussian line shape with a FWHM of $45 \mathrm{~cm}^{-1}$ for anthracene and $60 \mathrm{~cm}^{-1}$ for phenanthrene to match the experimental spectrum. As explained by Oomens et al. (2006), DFT calculations assume a linear absorption process, whilst the IRMPD process is inherently nonlinear. Band positions are most often well reproduced, but larger deviations may be observed for the band intensities.

The potential energy surface of the molecules was investigated using the Minnesota functional M06-2X with the same 

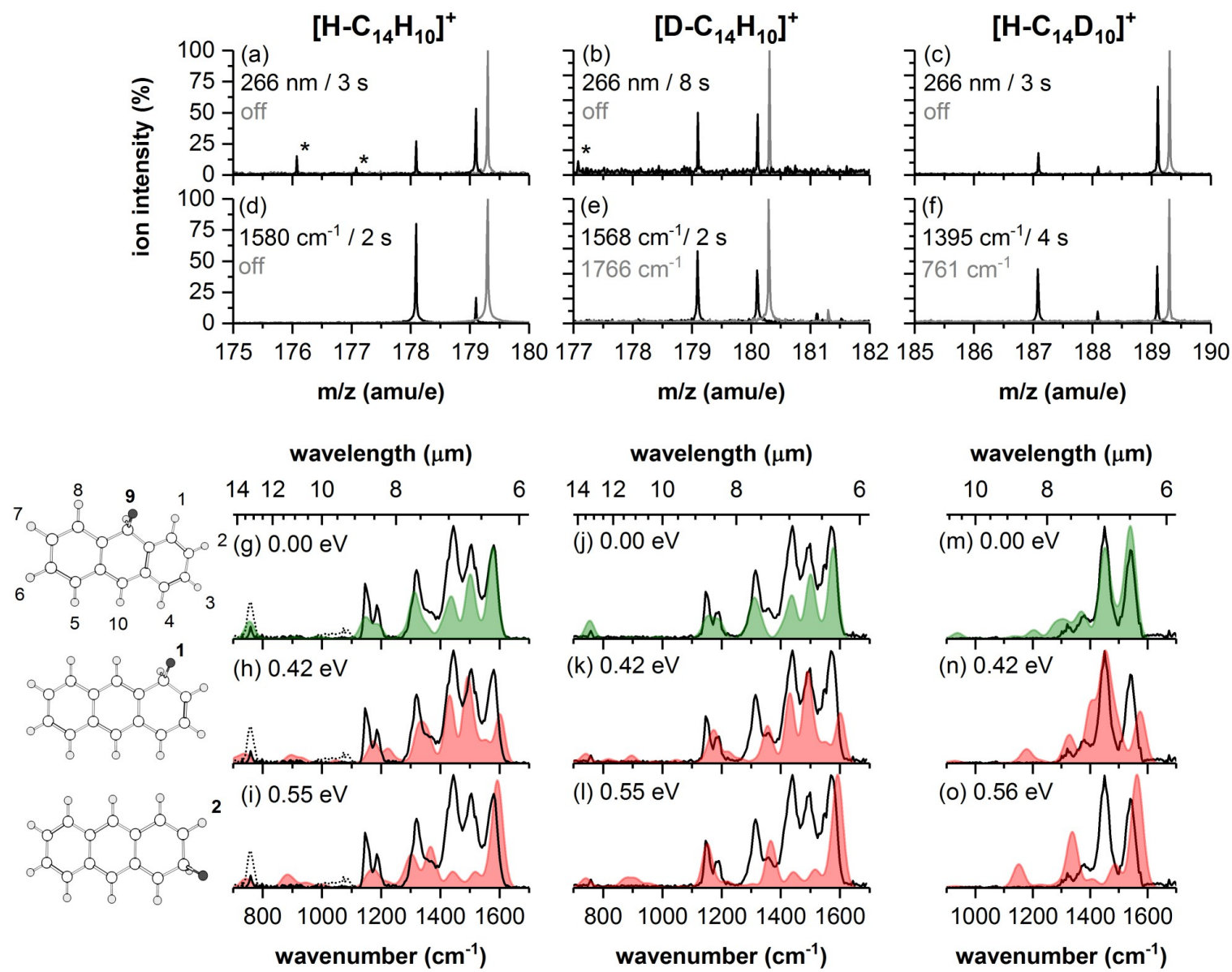

Fig. 1. Fragmentation mass (panels $a-f)$ and IRMPD spectra $(g-o)$ recorded for three different anthracene isotopologs: protonated anthracene $\left[\mathrm{H}-\mathrm{C}_{14} \mathrm{H}_{10}\right]^{+}, m / z=179.09$ (left column); deuteronated anthracene $-\left[\mathrm{D}-\mathrm{C}_{14} \mathrm{H}_{10}\right]^{+}, m / z=180.09$ (middle column); protonated, perdeuterated anthracene $-\left[\mathrm{H}-\mathrm{C}_{14} \mathrm{D}_{10}\right]^{+}, m / z=189.09$ (right column). For all mass spectra, black traces represent the fragmentation mass spectra, while gray traces are reference precursor mass spectra (with laser on or off-resonance). The gray traces are shifted up 0.2 amu to enhance their visibility. The top row are mass spectra following UV irradiation, the second row following IR irradiation at the indicated IR frequency. Experimental IR spectra are shown in black, superimposed on color shaded calculated spectra for each species with the protonation (deuteronation) site indicated in the structures left of the panels. The theoretical IR spectra were calculated using B3LYP/6-311++G(2d,p) and the ground-state energies in M06-2X/6-311++G(2d,p). Spectra that are considered to "match" are colored green; the ones that are considered to not match are red. Relative energies for each structure are shown above their respective spectra. The dotted curve in panels $g, h, i$ represents the measurement assisted by the $\mathrm{CO}_{2}$-laser.

basis set and was corrected for zero-point vibrational energies. This choice was motivated by the improved accuracy of M06$2 \mathrm{X}$ in predicting barrier energies and relative energies of isomers with respect to B3LYP (Zhao \& Truhlar 2008). Transition states (TSs) connecting the different structures of the $\left[\mathrm{H}-\mathrm{C}_{14} \mathrm{D}_{10}\right]^{+}$ isomers - in both anthracene and phenanthrene - were found with the Berny algorithm. To check that the calculated transition states connected the considered minimum structures, we animated the only mode with an imaginary frequency to confirm the proposed mechanism. Visualization of structures and vibrational modes was performed using the open-source program Gabedit (Allouche 2011).

\section{Results and discussion}

\subsection{Anthracene}

\subsubsection{UV and IR photofragmentation mass spectra}

We present both the UV and IR photodissociation mass spectra measured for the three isotopologs of anthracene. Figure 1 shows the mass spectra obtained with UV a,b,c and IRMPD photodissociation d,e,f. The gray curves show the precursor mass spectra recorded without irradiation, or with the IR laser off-resonance each offset by 0.2 amu for visualization. The black curves depict the fragmentation mass spectra after irradiation.

Figure 1a shows the UV measurement for protonated anthracene $\left[\mathrm{H}-\mathrm{C}_{14} \mathrm{H}_{10}\right]^{+}, m / z=179.09 \mathrm{amu}$. After irradiation, the precursor peak is depleted by approximately $50 \%$. Additionally, three fragment peaks are observed, which correspond to one to three $\mathrm{H}$ atom losses. The loss of one $\mathrm{H}$ atom leads to the formation of the radical cation $(m / z=178.08 \mathrm{amu})$. The two other fragment peaks denoted by asterisks most likely come from the dissociation of the radical cation and its ${ }^{13} \mathrm{C}$ isotopolog respectively - which both primarily lose two $\mathrm{H}$ atoms - as reported previously by Ekern et al. (1998) and confirmed by our UV measurements (see Fig. A.1).

Analogous measurements for deuteronated anthracene $\left[\mathrm{D}-\mathrm{C}_{14} \mathrm{H}_{10}\right]^{+}$are shown in Fig. $1 \mathrm{~b}, \mathrm{~m} / z=180.09 \mathrm{amu}$. Upon UV irradiation, the precursor mass is again depleted by approximately $50 \%$, and one fragment peak is observed that corresponds to the neutral loss of $1 \mathrm{amu}$. There is a slight indication (asterisk) of subsequent fragmentation of the radical cation as observed in Fig. 1a. Therefore, the deuteronated anthracene ion, like the protonated anthracene ion, only loses single hydrogen atoms. 
Finally, Fig. 1c shows the UV measurement for protonated, perdeuterated anthracene $\left[\mathrm{H}-\mathrm{C}_{14} \mathrm{D}_{10}\right]^{+}, m / z=189.14 \mathrm{amu}$. The precursor mass is slightly depleted in the fragmentation mass spectrum, and two fragment mass peaks are observed, associated with the loss of 1 and $2 \mathrm{amu}$, the former being the loss of an $\mathrm{H}$ atom and the latter the loss of a D atom. Importantly, the loss of 2 amu must correspond to the loss of a D atom as the loss of two $\mathrm{H}$ atoms is not possible here. The H/D loss ratio based on the integrated fragment intensities is $28 \% / 72 \%$, with an uncertainty of $\pm 5 \%$.

The IRMPD mass spectrum of protonated anthracene $\left[\mathrm{H}-\mathrm{C}_{14}\right.$ $\left.\mathrm{H}_{10}\right]^{+}$is depicted in Fig. 1d. A largely depleted precursor peak can be seen and, as expected, no dissociation of the radical cation is observed. Similar to the UV measurements, we only find the loss of single $\mathrm{H}$ atoms. For deuteronated anthracene $\left[\mathrm{D}-\mathrm{C}_{14} \mathrm{H}_{10}\right]^{+}$ (Fig. 1e) the fragmentation mass spectrum again shows a largely depleted precursor and a high-intensity fragment peak, corresponding to single $\mathrm{H}$ atom loss, similar to our observations for Fig. 1b. Lastly, in Fig. 1f, the fragmentation mass spectrum for protonated, perdeuterated anthracene $\left[\mathrm{H}-\mathrm{C}_{14} \mathrm{D}_{10}\right]^{+}$shows a precursor peak depleted by approximately half, and two fragment masses corresponding to the loss of $\mathrm{H}$ and $\mathrm{D}$, similar to that observed in Fig. 1c. The H/D loss ratio based on the integrated intensities is lower at $14 \% / 86 \%$, with an uncertainty of $\pm 1 \%$.

\subsubsection{Infrared spectra}

The IRMPD measurements also yield vibrational spectra that can be used to identify the structure of the precursor ion. Panels g-o of Fig. 1 present the IRMPD spectra of all three anthracene isotopologs (black curves), and compare them to our DFT calculated spectra for the different possible position isomers (shaded traces). For a detailed comparison, the reader is referred to the Appendix, where experimental and theoretical intensities and line positions are given in Tables A.1-A.3.

The IR spectra of protonated anthracene $\left[\mathrm{H}-\mathrm{C}_{14} \mathrm{H}_{10}\right]^{+}$are shown in panels g,h,i. The experimental spectrum displays at least seven features dominated by a triad of bands in the $1400-1600 \mathrm{~cm}^{-1}$ spectral range that are associated with $\mathrm{C}-\mathrm{C}$ stretching vibrations. In the $1100-1400 \mathrm{~cm}^{-1}$ range, three $\mathrm{C}-\mathrm{H}$ in-plane bending modes are observed. The best agreement is found between these peak positions and those of the predicted spectrum for the 9-isomer $(\mathrm{g})$, corresponding to the lowest-energy isomer for $\left[\mathrm{H}-\mathrm{C}_{14} \mathrm{H}_{10}\right]^{+}$. The predicted spectra for the other isomers (at 0.42 and $0.55 \mathrm{eV}$ higher in energy) agree less well: mismatches are observed for the experimental band at $1581 \mathrm{~cm}^{-1}$ and no bands are observed between 800 and $1000 \mathrm{~cm}^{-1}$, where bands are predicted for both other isomers. To ensure there are no bands in this frequency range, an additional measurement using a $\mathrm{CO}_{2}$ laser was performed to increase the intensity of the weak features (dotted curve). This only led to an intensity enhancement of the already observed band at $759 \mathrm{~cm}^{-1}$, which is a C-H out-of-plane quarto (i.e. involving four $\mathrm{H}$ atoms) bending vibration, but not to other bands, supporting the assignment of the 9-isomer. This result agrees with those of Knorke et al. (2009), who earlier reported an IRMPD spectrum of protonated anthracene in the $1000-1800 \mathrm{~cm}^{-1}$ range.

The IR spectra of deuteronated anthracene $\left[\mathrm{D}-\mathrm{C}_{14} \mathrm{H}_{10}\right]^{+}$are given in Figs. 1j,k,l. The shape is very similar to the spectrum of protonated anthracene, from which we can conclude that exchanging one hydrogen atom for a deuterium has little effect on the IR spectrum in the studied range. The largest difference is that the shoulder of the $1315 \mathrm{~cm}^{-1}$ band is now more clearly resolved, allowing us to identify the feature at $1360 \mathrm{~cm}^{-1}$ as a separate band associated with an in-plane $\mathrm{C}-\mathrm{H}$ bending vibration. The calculated spectrum for the lowest-energy 9-isomer again agrees best with the experimental spectrum.

The spectrum of protonated, perdeuterated anthracene $\left[\mathrm{H}-\mathrm{C}_{14} \mathrm{D}_{10}\right]^{+}$is displayed in the right column (Figs. 1m,n,o). The perdeuteration simplifies the spectrum, with only four clearly observed bands. Due to the higher mass of D, the C$\mathrm{D}$ out-of-plane bending modes shift to lower frequencies, leaving only the $\mathrm{C}-\mathrm{C}$ stretching vibrations in the $6-8 \mu \mathrm{m}$ range. The shape of the spectrum with two dominant peaks is excellently predicted by the calculated spectrum of the 9-isomer, depicted by the green curve in Fig. $1 \mathrm{~m}$. Panels $\mathrm{n}$ and o show that the 1 and 2-isomers provide a significantly poorer match than the 9isomer, making its assignment to the 9-isomer facile.

\subsubsection{Discussion}

The UV photofragmentation of fully aromatic radical $\mathrm{PAH}$ ions leads to predominantly sequential loss of two $\mathrm{H}$ atoms and to a lesser extent to loss of $\mathrm{H}_{2}$ (Ekern et al. 1998; Ling \& Lifshitz 1998; Rodriguez Castillo et al. 2018). In both cases, the result is a loss of two $\mathrm{H}$-atoms. The loss of single $\mathrm{H}$ or $\mathrm{D}$ atoms must therefore be attributed to a loss from protonated/deuteronated species, which possess aromatic $\mathrm{C}-\mathrm{H} / \mathrm{C}-\mathrm{D}$ sites and one aliphatic $\mathrm{C}-\mathrm{H} / \mathrm{C}-\mathrm{D}$ site. Our calculations show a binding energy for $\mathrm{H}$-loss (D-loss) from an aliphatic site of $2.6 \mathrm{eV}(2.7 \mathrm{eV})$, whereas from an aromatic site this energy is $4.7 \mathrm{eV}(4.8 \mathrm{eV})$, in agreement with a recent experimental study (West et al. 2018).

Therefore, H/D loss is very likely from aliphatic sites only. Both isotopologs only have a single aliphatic site from which $\mathrm{H}$ or $\mathrm{D}$ can be eliminated. The zero-point-energy-corrected binding energy for aliphatic $\mathrm{C}-\mathrm{D}$ is only marginally higher than for $\mathrm{C}-\mathrm{H}$, so large differences in the $\mathrm{H} / \mathrm{D}$ loss rates are a priori not expected. We observe that for $\left[\mathrm{D}-\mathrm{C}_{14} \mathrm{H}_{10}\right]^{+}$, photofragmentation only results in the loss of single $\mathrm{H}$ atoms, for both IRMPD and $\mathrm{UV}$ dissociation. For $\left[\mathrm{H}-\mathrm{C}_{14} \mathrm{D}_{10}\right]^{+}$, the opposite appears to happen, with mainly single $\mathrm{D}$ atom loss, and a small $\mathrm{H}$ atom loss channel. The observed large deviations from a 50/50 H/D loss ratio suggest that the molecule undergoes dynamics before dissociation, where the extra $\mathrm{H}$ or $\mathrm{D}$ atom attached in the protonation/deuteronation process has migrated away from the aliphatic site.

To investigate this migration further, we consider a mechanism in which $\mathrm{H}$ and $\mathrm{D}$ atoms can move from one carbon site to the next, leading to a population of $\left[\mathrm{D}-\mathrm{C}_{14} \mathrm{H}_{10}\right]^{+}$with a mix of aliphatic $\mathrm{C}-\mathrm{HH}$ and $\mathrm{C}-\mathrm{HD}$ groups, or in $\left[\mathrm{H}-\mathrm{C}_{14} \mathrm{D}_{10}\right]^{+}$with a mix of aliphatic $\mathrm{C}-\mathrm{DD}$ and $\mathrm{C}-\mathrm{HD}$ groups. Taking the 1 -isomer of $\left[\mathrm{D}-\mathrm{C}_{14} \mathrm{H}_{10}\right]^{+}$as an example, the $\mathrm{H}$ atom of the $\mathrm{C}-\mathrm{HD}$ group can migrate to the neighboring 2-site, turning it into an aliphatic $\mathrm{C}-\mathrm{HH}$ group while leaving an aromatic $\mathrm{C}-\mathrm{D}$ site behind. This will lead to an increased H/D loss ratio in the photodissociation mass spectra. Alternatively, the $\mathrm{D}$ atom can move, resulting in a shift of the $\mathrm{C}-\mathrm{HD}$ on site 1 to a $\mathrm{C}-\mathrm{HD}$ on site 2 . This shift will however not have consequences for the fragmentation propensities.

This 1,2-hydrogen (or deuterium) shift is a well-known phenomenon in organic chemistry (Whitmore 1932; Kuck 2002; Bruice 2014), and specifically for reactions in aromatic molecules (Brooks \& Scott 1999). Furthermore, in theoretical studies of PAH species, the 1,2-H shift across the PAH rim has been shown to occur once they are excited to internal energies above $1 \mathrm{eV}$, leading to the formation of various intermediate isomers containing a C-HH group (Jolibois et al. 2005; 


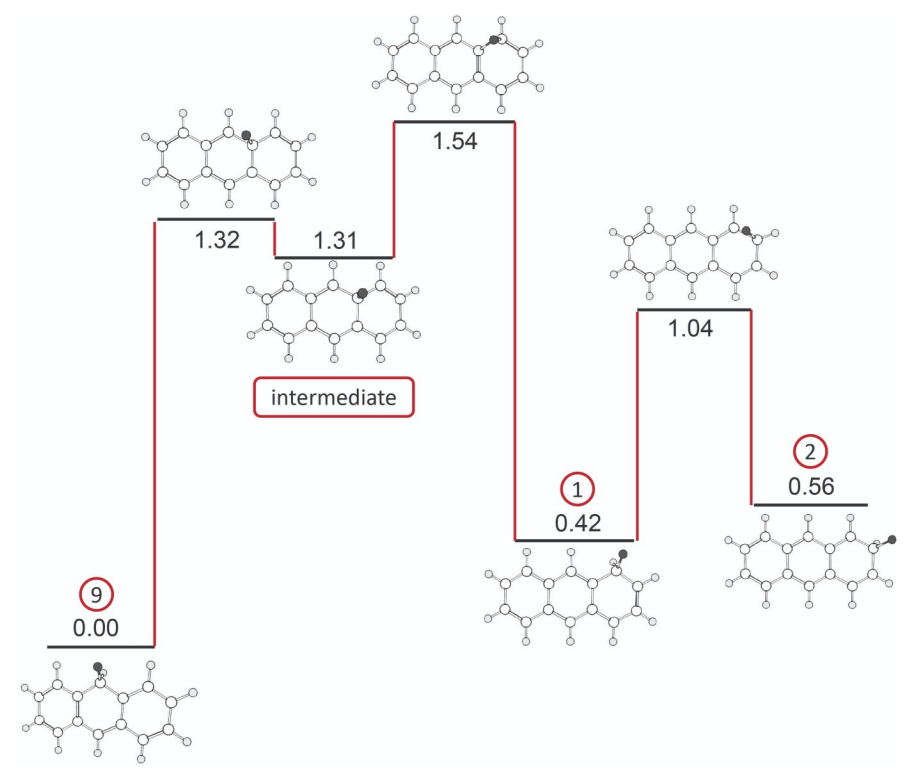

Fig. 2. Potential energy surface for $D$ migration linking the isomers of protonated, perdeuterated anthracene, $\left(\left[\mathrm{H}-\mathrm{C}_{14} \mathrm{D}_{10}\right]^{+}\right)$with energies in $\mathrm{eV}$, calculated using M06-2X/6-311++G(2d,p). The migrating $\mathrm{D}$ atom is highlighted in black.

Trinquier et al. 2017; Castellanos et al. 2018a). Using DFT, we calculated the potential energy reaction pathway for $\mathrm{D}$ migration along $\left[\mathrm{H}-\mathrm{C}_{14} \mathrm{D}_{10}\right]^{+}$, and the results are depicted in Fig. 2. The molecular structures of the three unique position isomers are shown, connected through transition states, including one relatively stable intermediate state where the D is out-of-plane bound to a tertiary carbon. This reactive pathway reveals that the highest barrier is $1.54 \mathrm{eV}$, which is well below the C-D bond fragmentation energy of $2.7 \mathrm{eV}$. In the current experiments, the IR spectra indicate the presence of only the lowest energy protonation isomer, but we are unable to discern different aromatic C-D attachment sites for the observed 9-isomer (see Fig. A.2). While we cannot fully rule out that $1,2-\mathrm{H}$ or -D shifts occur during the ESI, the absence of different position isomers that are approximately $0.5 \mathrm{eV}$ higher in energy suggests that such high barriers are not overcome in the ESI. On the other hand, we can be certain they are energetically allowed upon photoexcitation, given the energy requirements for fragmentation.

In order to assess whether the mobility of atomic $\mathrm{H}$ or $\mathrm{D}$ is sufficiently high to rationalize the observed propensities for $\mathrm{H}$ - and D-loss for $\left[\mathrm{D}-\mathrm{C}_{14} \mathrm{H}_{10}\right]^{+}$and $\left[\mathrm{H}-\mathrm{C}_{14} \mathrm{D}_{10}\right]^{+}$, it is important to get quantitative information on the different reaction rates involved. We performed RRKM theory rate calculations (Baer \& Mayer (1997); see Castellanos et al. (2018a) for a detailed description) for both $\mathrm{H}$ shifts and $\mathrm{D}$ shifts on both isomers, starting from the 1-isomer and moving towards the 2isomer (see Fig. 2 for a visual representation). The 1-to-2 shift was chosen as an example due to its relative simplicity compared to the 1-to-9 shift, which would involve two transition states and one intermediate state. The rates plotted as a function of internal energy can be found in Fig. 3 and the rates for three specific energies are listed in Table 1. These three energies represent the highest calculated energy barrier for H/D-shifts $(0.64 \mathrm{eV}$ in $\left[\mathrm{D}-\mathrm{C}_{14} \mathrm{H}_{10}\right]^{+}$, see Table 1), the lowest energy required for $\mathrm{H}$-loss $(2.7 \mathrm{eV})$, and the UV photon energy $(4.7 \mathrm{eV})$, respectively. We observe the following: (1) The $\mathrm{H}$-shift rate is consistently higher than that of the D shift. (2) The lower the internal energy, the larger the difference in $\mathrm{H}$ - and D-shift rates.
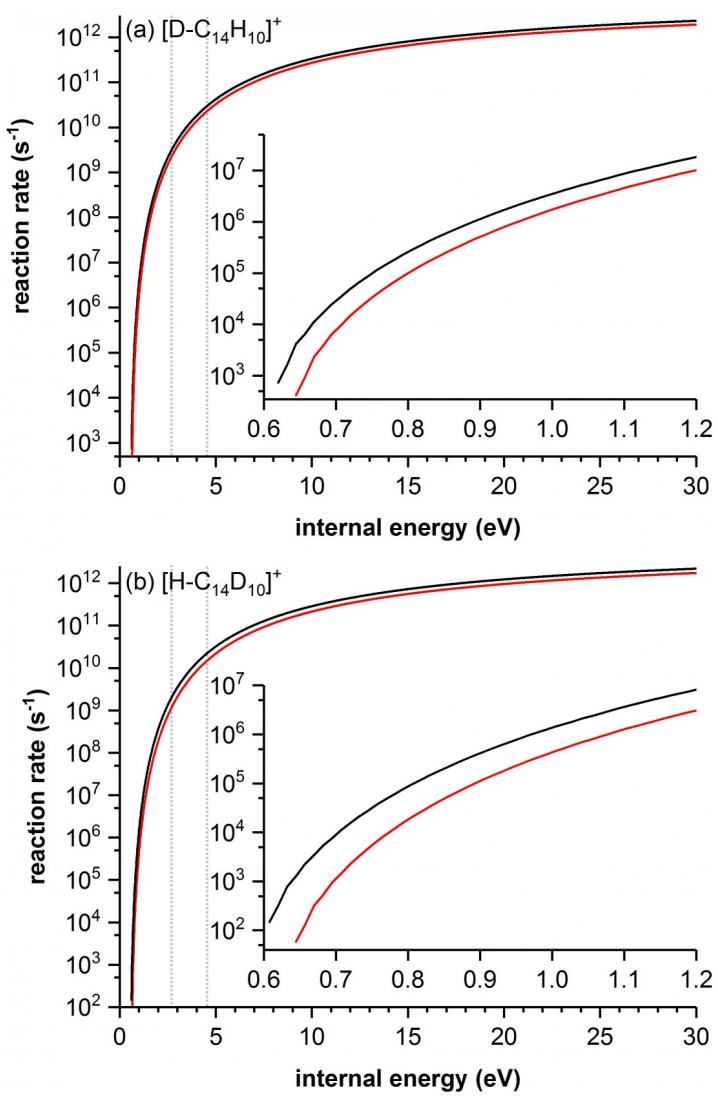

Fig. 3. RRKM reaction rate calculations for the 1-to- $2 \mathrm{H} / \mathrm{D}$-shifts of (a) deuteronated anthracene, $\left[\mathrm{D}-\mathrm{C}_{14} \mathrm{H}_{10}\right]^{+}$and $(b)$ protonated, perdeuterated anthracene, $\left[\mathrm{H}-\mathrm{C}_{14} \mathrm{D}_{10}\right]^{+}$from the 1-isomer to the 2-isomer, plotted as a function of the internal energy of the molecule in $\mathrm{eV}$. In both $(a)$ and (b), the black curves depict the hydrogen shifting rates and the red curves depict the $\mathrm{D}$ shifting rates. Dotted lines depict internal energies attained through IR (min. 2.7 eV) and UV (max. $4.7 \mathrm{eV}$ ) excitation.

For $0.64 \mathrm{eV}$, the reaction rates differ by an order of magnitude. (3) The shift rates for both the $\left[\mathrm{D}-\mathrm{C}_{14} \mathrm{H}_{10}\right]^{+}$and $\left[\mathrm{H}-\mathrm{C}_{14} \mathrm{D}_{10}\right]^{+}$ isomers plateau around $10^{12} \mathrm{~s}^{-1}$ with increasing internal energies. However, shift rates on $\left[\mathrm{H}-\mathrm{C}_{14} \mathrm{D}_{10}\right]^{+}$are lower and exhibit a more pronounced difference between the $\mathrm{H}$ - and D-shifting rates than for $\left[\mathrm{D}-\mathrm{C}_{14} \mathrm{H}_{10}\right]^{+}$. (4) Finally, and most importantly, all rates are so high at the internal energies achieved in both IR and UV experiments that a reaction equilibrium would be reached well within the time frame of our experiment. Although the barriers for other shift reactions are higher (e.g., from the 1- to the 9-position), the current rates are at least four orders of magnitude larger than our experimental time window $\left(10^{-5} \mathrm{~s}\right)$. It is therefore clear that shifts to all different sites on the molecule will occur. This is the equilibrium state in which a mixture of different position isomers exists that will differ between isotopologs, and that we refer to as full scrambling.

Purely statistically speaking and assuming full scrambling, $10 \%$ of the aliphatic groups in both the $\left[\mathrm{D}-\mathrm{C}_{14} \mathrm{H}_{10}\right]^{+}$and $\left[\mathrm{H}-\mathrm{C}_{14} \mathrm{D}_{10}\right]^{+}$isotopologs are $\mathrm{C}-\mathrm{HD}$ groups. Disregarding any difference in probability to eliminate an $\mathrm{H}$ or $\mathrm{D}$ atom from that group, one would expect 5\% D-loss from [D- $\left.\mathrm{C}_{14} \mathrm{H}_{10}\right]^{+}$and $5 \%$ $\mathrm{H}$-loss from $\left[\mathrm{H}-\mathrm{C}_{14} \mathrm{D}_{10}\right]^{+}$. Table 2 lists these statistical factors together with the measured UV and IR photofragmentation factors of both isotopologs. Comparison with the experiment shows that the measured hydrogen loss exceeds the statistical probability, whereas the measured deuterium loss falls short in both isotopologs. This difference can be attributed to the differences 
Table 1. Barrier heights $E_{\mathrm{b}}$ calculated for 1-to-2 shift reaction for the studied species, and RRKM calculated reaction rates at selected internal energies $E_{\mathrm{i}}$.

\begin{tabular}{llllll}
\hline \hline & & & \multicolumn{3}{c}{ RRKM rates $\left(\mathrm{s}^{-1}\right)$} \\
\cline { 4 - 6 } & & & \multicolumn{3}{c}{ for $E_{\mathrm{i}}(\mathrm{eV})$} \\
\cline { 4 - 6 } Species & Atom & $E_{\mathrm{b}}(\mathrm{eV})$ & 0.64 & 2.7 & 4.7 \\
\hline$\left[\mathrm{D}-\mathrm{C}_{14} \mathrm{H}_{10}\right]^{+}$ & $\mathrm{H}$ & 0.61 & $4.1 \times 10^{3}$ & $3.2 \times 10^{9}$ & $3.3 \times 10^{10}$ \\
{$\left[\mathrm{D}-\mathrm{C}_{14} \mathrm{H}_{10}\right]^{+}$} & $\mathrm{D}$ & 0.64 & $4.1 \times 10^{2}$ & $2.3 \times 10^{9}$ & $2.5 \times 10^{10}$ \\
\hline$\left[\mathrm{H}-\mathrm{C}_{14} \mathrm{D}_{10}\right]^{+}$ & $\mathrm{H}$ & 0.61 & $1.3 \times 10^{3}$ & $2.0 \times 10^{9}$ & $2.4 \times 10^{10}$ \\
{$\left[\mathrm{H}-\mathrm{C}_{14} \mathrm{D}_{10}\right]^{+}$} & $\mathrm{D}$ & 0.64 & 58 & $1.2 \times 10^{9}$ & $1.6 \times 10^{10}$ \\
\hline
\end{tabular}

Table 2. Observed relative propensities or H- and D-loss for IR and UV experiments.

\begin{tabular}{c|cc|cc|cc}
\hline \hline & \multicolumn{2}{|c|}{ UV excited } & \multicolumn{2}{c|}{ IR excited } & \multicolumn{2}{c}{ Full scrambling } \\
\hline & H & D & H & D & H & D \\
\hline$\left[\mathrm{D}-\mathrm{C}_{14} \mathrm{H}_{10}\right]^{+}$ & 100 & 0 & 100 & 0 & 95 & 5 \\
{$\left[\mathrm{H}-\mathrm{C}_{14} \mathrm{D}_{10}\right]^{+}$} & 28 & 72 & 14 & 86 & 5 & 95 \\
\hline
\end{tabular}

in the migration rates discussed above, which leads to different mobility and loss rates for the $\mathrm{D}$ and $\mathrm{H}$ atoms.

From these migration rates, it can be seen that $\mathrm{H}$ is more likely to shift than $\mathrm{D}$, which in $\left[\mathrm{D}-\mathrm{C}_{14} \mathrm{H}_{10}\right]^{+}$results in an isomer in which an aromatic $\mathrm{C}-\mathrm{D}$ is left behind and an aliphatic $\mathrm{C}-\mathrm{HH}$ is created. From the perspective of this new $\mathrm{C}-\mathrm{HH}$, the next shift will either lead to a new $\mathrm{C}-\mathrm{HH}$ or back to the $\mathrm{C}-\mathrm{HD}$. If the $\mathrm{D}$ had begun to shift, the C-HD site would have shifted position, and the odds would be higher for the next shift to be with the $\mathrm{H}$ atom, both leading to a $\mathrm{C}-\mathrm{HH}$. This means that not only does the zero-point energy difference in binding energy lead to preferential $\mathrm{H}$ atom loss in the case of a C-HD site, but also that the larger mobility will lead to preferential creation of $\mathrm{C}-\mathrm{HH}$ sites. In the case of $\left[\mathrm{H}-\mathrm{C}_{14} \mathrm{D}_{10}\right]^{+}$, the $\mathrm{H}$ atom will simply create another C-HD site. The shift of a D atom will lead to a C-DD site from which $\mathrm{D}$ atom loss may occur.

\subsection{Phenanthrene}

We further investigated the scrambling mechanism by performing experiments on phenanthrene- $\mathrm{D}_{10}$, a three-ringed PAH with a nonlinear structure.

\subsubsection{Infrared photofragmentation mass spectrum}

Figure 4a shows the IRMPD mass spectrum of protonated, perdeuterated phenanthrene $\left(\left[\mathrm{H}-\mathrm{C}_{14} \mathrm{D}_{10}\right]^{+}\right), m / z=189.14 \mathrm{amu}$. The color coding, offsetting, and normalization are identical to that of the anthracene mass spectra. In the fragmentation mass spectrum, the precursor peak is depleted by more than $30 \%$ and two fragment peaks are observed, displaying the dominant loss of $2 \mathrm{amu}$ and smaller loss of $1 \mathrm{amu}$, amounting to an integrated $\mathrm{H} / \mathrm{D}$ loss ratio of $14 \% / 86 \%$ with an uncertainty of $\pm 4 \%$.

\subsubsection{Infrared spectrum}

The experimental IR spectrum of $\left[\mathrm{H}-\mathrm{C}_{14} \mathrm{D}_{10}\right]^{+}$is displayed by the black curves in Figs. $4 \mathrm{~b}-\mathrm{f}$. The theoretical spectra for the five possible structural isomers are shown as the blue shaded traces. They are listed in order of increasing energy, from top to bottom. The experimental IR spectrum shows three main features in the $\mathrm{C}-\mathrm{C}$ stretching region between 1300 and $1600 \mathrm{~cm}^{-1}$. No features appear in the $1000-1200 \mathrm{~cm}^{-1}$ region. The shape is roughly reproduced by the predicted lowest energy 9-isomer in Fig. 4b. The 4-isomer (Fig. 4e), which lies only $0.05 \mathrm{eV}$ higher, also matches the experiment well. The remaining three theoretical spectra do not reproduce the shape of the features in the experiment, and show significantly more IR activity in the 1000$1200 \mathrm{~cm}^{-1}$ region than the 9-isomer and 4-isomer. We nevertheless conclude that it is likely that under our experimental conditions several isomers are present in significant amounts, in contrast to anthracene where only one isomer was present. Although this hinders a conclusive assignment of the IR spectrum, it does not affect the discussion on the proposed scrambling mechanism as becomes clear below.

\subsubsection{Discussion}

We find a clear indication that phenanthrene- $\mathrm{D}_{10}$ undergoes a scrambling mechanism similar to that for anthracene- $D_{10}$. As can be observed in Fig. 4a, phenanthrene- $\mathrm{D}_{10}$ exhibits dominant $\mathrm{D}$ atom loss and little $\mathrm{H}$ atom loss, a behavior very similar to anthracene- $\mathrm{D}_{10}$ in Figs. 1c,f. The H/D loss ratio of phenanthrene is the same as the ratio for anthracene, albeit with a larger uncertainty. It is interesting that the measured H/D ratios of IRMPD-fragmented $\left[\mathrm{H}-\mathrm{C}_{14} \mathrm{D}_{10}\right]^{+}$are the same for both anthracene and phenanthrene, considering that their potential energy surfaces are different. The protonation isomer energies of phenanthrene are an order of magnitude closer together than those of anthracene. At room temperature, it is likely that the precursor phenanthrene ions exist in a mixture of multiple isomers, whereas only one precursor 9-isomer is present for anthracene.

The structural difference leads to differing energy barriers and therefore scrambling rates (see Figs. 2 and 5). The major rate-limiting step for full scrambling in phenanthrene as well as in anthracene is the shift from the 9- to the 1- position, for which the hydrogen has to move across a nonhydrogenated tertiary carbon, which is bound to three other carbons. Crossing this tertiary carbon is associated with an energy barrier of $1.54 \mathrm{eV}$ for anthracene, which is 1.6 times higher than the analogous barrier of $0.97 \mathrm{eV}$ for phenanthrene. Scrambling is therefore expected to be substantially faster for phenanthrene. Moreover, the initial aliphatic C-HD group in anthracene is located on a solo site from which migration to either neighboring sites is associated with a barrier of $1.54 \mathrm{eV}$. Thus, for any - even partial - scrambling to occur before photolysis of anthracene, this highest barrier needs to be overcome. For phenanthrene, the initial aliphatic C-HD group is located on a duo or quarto site, already allowing for partial scrambling to occur on the same aromatic ring at relatively low energies. Partial scrambling on nonsolo sites is therefore not only faster, but also possible at lower excitation energies or temperatures. That the measured H/D ratios are the same for both $\left[\mathrm{H}-\mathrm{C}_{14} \mathrm{D}_{10}\right]^{+}$isomers indicates that full scrambling is easily achieved before dissociation for these small molecules. 

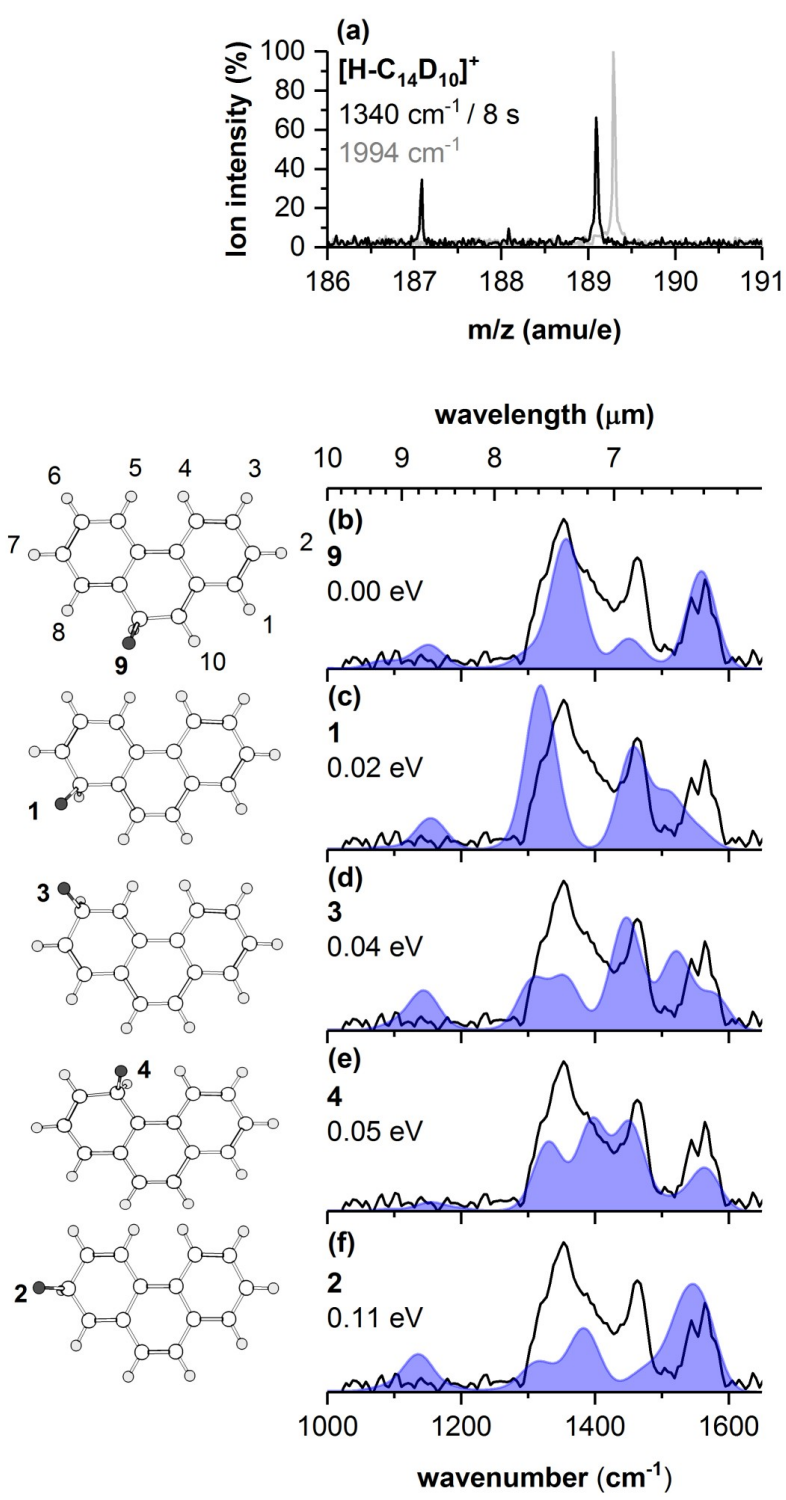

Fig. 4. Infrared photofragmentation (panel $a$, black trace) and reference precursor (gray trace, shifted up $0.2 \mathrm{amu}$ ) mass spectra, and IRMPD spectrum (panels $b-f$, black trace) for protonated, perdeuterated phenanthrene $-\left[\mathrm{H}-\mathrm{C}_{14} \mathrm{D}_{10}\right]^{+}$. Panels $b-f$ further contain calculated spectra (blue) for five different position isomers, for which the structures are shown on the left. The theoretical IR spectra were calculated using $\mathrm{B} 3 \mathrm{LYP} / 6-311++\mathrm{G}(2 \mathrm{~d}, \mathrm{p})$ and the ground-state energies in M06-2X/6$311++\mathrm{G}(2 \mathrm{~d}, \mathrm{p})$.

This makes sense considering that our experiment takes place on microsecond timescales, and our calculated rates imply a much faster scrambling process.

\section{Astrophysical implications}

Gas-phase hydrogenation of PAH molecules has been studied both theoretically and experimentally (see Thrower et al. 2012; Klærke et al. 2013; Cazaux et al. 2016, 2019; Vala et al. 2017; Ferullo et al. 2019), because it plays a role in shaping the PAH populations in the more shielded environments of photodissociation regions (PDRs; Montillaud et al. 2013; Boschman et al. 2015; Andrews et al. 2016). Singly and even multiply hydrogenated PAHs are able to maintain their hydrogenation state in these shielded regions, allowing for the catalytic forma- tion of $\mathrm{H}_{2}$ (Wakelam et al. 2017). For large ( $>50$ carbons) molecules, multi-photon excitation is required for $\mathrm{H}$-loss to occur (Montillaud et al. 2013; Andrews et al. 2016). The mechanism for these interstellar loss processes has been studied experimentally, and the roaming of hydrogen atoms on hydrogenated PAHs has been recently put forward to explain the experimental results for $\mathrm{H} / \mathrm{H}_{2}$ photodissociation in large PAHs (Castellanos et al. 2018a,b).

Doney et al. (2016) detected deuterium-containing PAHs via their C-D stretches in astronomical objects with intense aliphatic $\mathrm{C}-\mathrm{H}$ bands. In these regions, the aliphatic to aromatic $\mathrm{H}$ ratio inferred from the ratio of the 3.4 and $3.29 \mu \mathrm{m}$ band intensities is $0.2-0.3$, almost an order of magnitude larger than typically observed for PAHs in the ISM (Tielens 2008). This suggests that D-containing PAHs are predominantly present in regions that favor hydrogenation or deuteration. These regions correspond to the more shielded layers of PDRs, with $G_{0} / n(\mathrm{H})$ values smaller than 0.03 (Andrews et al. 2016). The additional $\mathrm{H} / \mathrm{D}$ atom preferably attaches to the edge of hydrogenated PAH molecules, with low to no barriers, creating aliphatic groups (Rauls \& Hornekær 2008). Our study shows that upon hydrogenation or deuteration, and irradiation, PAHs are prone to facile scrambling.

The calculated reaction barriers for the 1,2-H/D shifts (shown in Figs. 2 and 5) are at least $1.2 \mathrm{eV}$ lower than the energies supplied by the photo-excitation processes in this study, and are clearly below the energy of interstellar UV radiation (Allamandola et al. 1989; Montillaud et al. 2013). This implies that for PAHs that are able to withstand interstellar radiation without losing $\mathrm{H}$ or D atoms, scrambling would inevitably occur. As shown by the RRKM rate calculations, 1,2-H shifts have higher reaction rates than the equivalent 1,2-D shifts, which creates a bias towards aliphatic $\mathrm{C}-\mathrm{HH}$ groups over $\mathrm{C}-\mathrm{HD}$ groups on PAHs with low deuteration levels ( 1 or $2 \mathrm{D}$ atoms). While the D-PAH molecule is exposed to a stronger UV field, aliphatic $\mathrm{H}$ will be preferably lost over D. Similarly, this mechanism could lead to the uptake and preservation of multiple D atoms on the molecule, up to a point where the higher probability of C-DD site formation leads to $\mathrm{D}$ loss being favored over $\mathrm{H}$ loss. From a spectroscopic point of view, this process could be traced looking at the intensity variation of the aliphatic $\mathrm{C}-\mathrm{H} /$ aromatic $\mathrm{C}-\mathrm{D}$ stretching bands $(3.4 / 4.4$ and $3.5 / 4.4 \mu \mathrm{m})$ with a spatially resolved study of an extended source like IRAS 12073-6233, which shows hints of spatial variation of the $\mathrm{D} / \mathrm{H}$ ratio (Doney et al. 2016).

Large, compact PAHs - which are believed to be the most abundant class of PAHs in the ISM (Ricca et al. 2012) - are expected to exhibit more pronounced effects. Solo sites are more abundant on compact PAHs and are highly reactive (Aihara et al. 1996), meaning that D is most likely to attach itself there and stay there due to the meta-stable tertiary carbon neighbor sites (see Figs. 2 and 5). Furthermore, the absorbed photon energy will be distributed over many more vibrational modes in a large $\mathrm{PAH}$ than in small PAHs, leading to lower average excitation per vibrational state. Because the difference in scrambling and dissociation behavior of $\mathrm{H}$ and $\mathrm{D}$ atoms is larger at lower energies, this means that the larger the PAH molecule, the more pronounced the mobility difference between $\mathrm{D}$ and $\mathrm{H}$. Based on these considerations, we speculate that large, compact PAHs with an aliphatic C-HD group on solo sites might cause a shift in the position of the aliphatic C-D stretching bands around $4.75 \mu \mathrm{m}$, as was also observed in calculations for deuteronated ovalene by Buragohain et al. (2016). A full calculation for large PAHs is beyond the scope of this paper, and will be included in future 


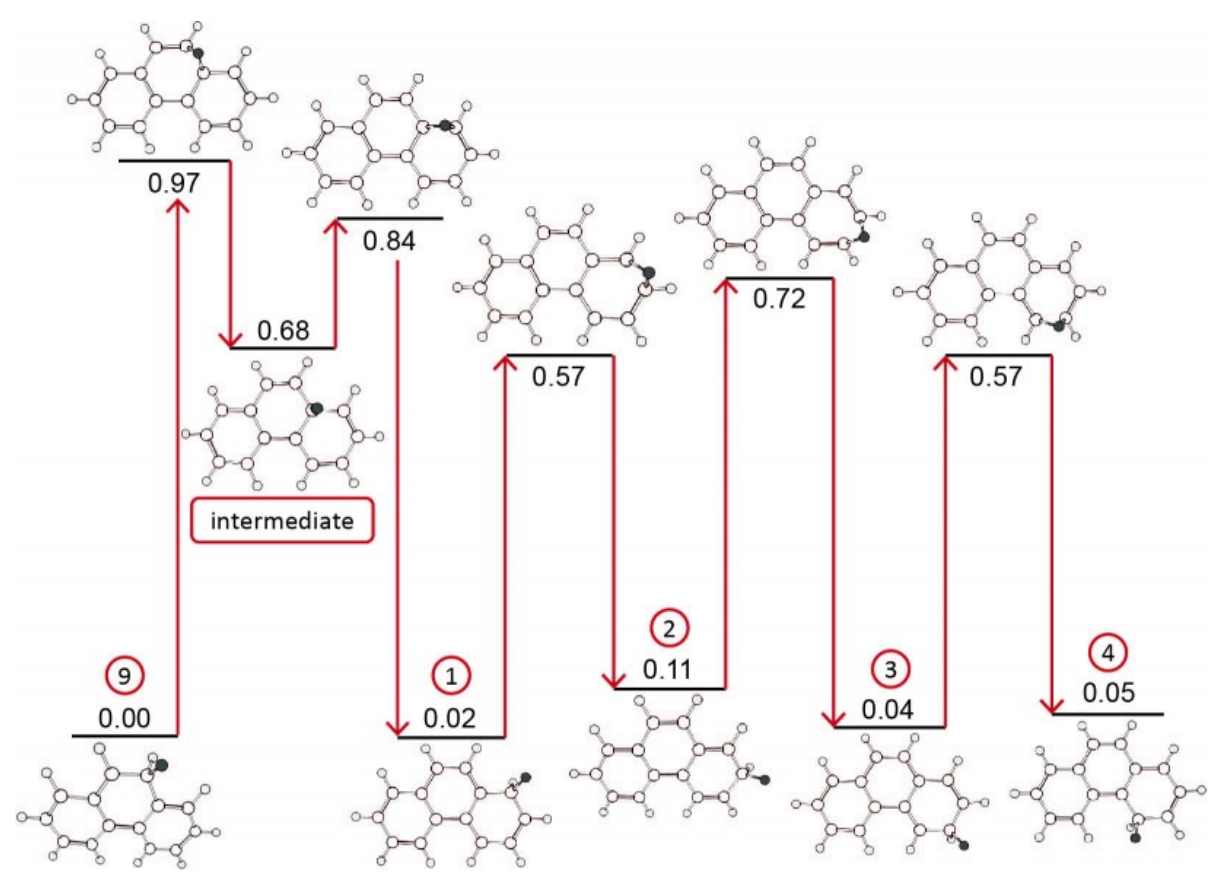

Fig. 5. Isomers of protonated, perdeuterated phenanthrene and their transition states, with corresponding energies in $\mathrm{eV}$ calculated with M06-2X/6-311++G(2d,p). work (Wiersma et al., in prep.). The upcoming James Webb Space Telescope mission will provide improved spatial resolution and sensitivity compared to Spitzer and AKARI, which should make it possible to observe new regions and provide us with greater detail for the already well-known ones. Finally, new photochemical models including the effect of scrambling are needed to determine the role of PAHs as possible deuterium reservoirs.

\section{Conclusion}

We present the UV and IR photofragmentation mass spectra of deuterium-containing isotopologs of protonated anthracene and phenanthrene. These fragmentation mass spectra demonstrate that singly deuteronated molecules do not show D atom loss, while the protonated, perdeuterated molecules show dominant D atom loss and low $\mathrm{H}$ atom loss. Supported by DFT and RRKM rate calculations of 1,2-H/D shift reactions, we show that these observations can only be explained by a mechanism that allows $\mathrm{H}$ and $\mathrm{D}$ to roam over the peripheral carbon atoms, leading to a "scrambling" of different isomers, which will readily occur upon absorption of interstellar UV photons. The scrambling of the $\mathrm{H}$ and $\mathrm{D}$ atoms across the carbon skeleton rim has several important implications for the chemistry of larger PAHs in the ISM. One of these implications is that large PAHs can take up several deuterium atoms by "locking" them on aromatic sites. This would suggest that the deuterium fractionation on PAHs could be higher than previously modeled. We also postulate that aliphatic C-HD solo sites may be more abundant than other configurations, which is due to the elevated barriers for 1,2-H/D shifts across carbon sites and the relative reactivity of solo sites. To test our hypotheses, new photochemical modeling and a re-evaluation of observational data are needed.

Acknowledgements. We gratefully acknowledge the Nederlandse Organisatie voor Wetenschappelijk Onderzoek (NWO) for the support of the FELIX Laboratory. This work is supported by the VIDI grant (723.014.007) of A. P. from NWO. Furthermore, A. C. gratefully acknowledges NWO for a VENI grant (639.041.543). Calculations were carried out on the Dutch national e-infrastructure (Cartesius and LISA) with the support of Surfsara, under projects NWO Rekentijd 16260 and 17603. Part of this work was inspired by the COST
Action CM1401 "Our Astro-Chemical History". S. W. would also like to thank dr. Mridusmita Buragohain for the fruitful discussions.

\section{References}

Aihara, J., Fujiwara, K., Harada, A., et al. 1996, J. Mol. Struct., 366, 219 Allamandola, L. J., Tielens, A. G. G. M., \& Barker, J. R. 1989, ApJS, 71, 733 Allouche, A. 2011, J. Comput. Chem., 32, 174

Almasian, M., Grzetic, J., van Maurik, J., et al. 2012, J. Phys. Chem. Let., 3, 2259

Andrews, H., Candian, A., \& Tielens, A. G. G. M. 2016, A\&A, 595, A23

Baer, T., \& Mayer, P. M. 1997, J. Am. Soc. Mass Spectrom., 8, 103

Bauschlicher, C. W., \& Ricca, A. 2010, Mol. Phys., 108, 2647

Bauschlicher, C. W., Langhoff, S. R., Sandford, S. A., \& Hudgins, D. M. 1997, J. Phys. Chem. A, 101, 2414

Becke, A. D. 1993, J. Chem. Phys., 98, 5648

Berné, O., \& Tielens, A. G. G. M. 2012, PNAS, 109, 401

Berné, O., Mulas, G., \& Joblin, C. 2013, A\&A, 550, L4

Boschman, L., Cazaux, S., Spaans, M., Hoekstra, R., \& Schlathölter, T. 2015, A\&A, 579, A72

Brooks, M. A., \& Scott, L. T. 1999, J. Am. Chem. Soc., 121, 5444

Bruice, P. Y. 2014, Organic Chemistry: Pearson International Edition, 7th edn. (Pearson Education Limited), 258

Buragohain, M., Pathak, A., Sarre, P., Onaka, T., \& Sakon, I. 2015, MRNAS, 454, 201

Buragohain, M., Pathak, A., Sarre, P., Onaka, T., \& Sakon, I. 2016, Planet. Space Sci., 133, 97

Cami, J., Bernard-Salas, J., Peeters, E., \& Malek, S. E. 2010, Sci, 329, 1180

Campbell, E. K., Holz, M., Gerlich, D., \& Maier, J. P. 2015, Nature, 523, 322

Castellanos, P., Candian, A., Zhen, J., Linnartz, H., \& Tielens, A. G. G. M. 2018a, A\&A, 616, A166

Castellanos, P., Candian, A., Andrews, H., \& Tielens, A. G. G. M. 2018b, A\&A, 616, A167

Cazaux, S., Boschman, L., Rougeau, N., et al. 2016, Sci. Rep., 6, 19835

Cazaux, S., Arribard, Y., Egorov, D., et al. 2019, ApJ, 875, 27

Cernicharo, J., Heras, A. M., Tielens, A. G. G. M., et al. 2001, ApJ, 546, L123

Cordiner, M. A., Linnartz, H., Cox, N. L. J., et al. 2019, ApJ, 875, L28

Doney, K. D., Candian, A., Mori, T., Onaka, T., \& Tielens, A. G. G. M. 2016, A\&A, 586, A65

Draine, B. T. 2006, in Astrophysics in the Far Ultraviolet, Five Years of Discovery with FUSE, eds. G. Sonneborn, H. Moos, \& B. G. Andersson, ASP Conf. Ser., 348, 58

Ekern, S. P., Marshall, A. G., Szczepanski, J., \& Vala, M. 1998, J. Phys. Chem. A, 102, 3498

Epstein, R. I., Lattimer, J. M., \& Schramm, D. N. 1976, Nature, 263, 198 
Ferullo, R. M., Zubieta, C. E., \& Belelli, P. G. 2019, Phys. Chem. Chem. Phys., 21,12012

Frisch, M. J., Trucks, G. W., Schlegel, H. B., et al. 2009, Gaussian 09 Revision D.01, Gaussian Inc., Wallingford CT

Hudgins, D. M., Sandford, S. A., \& Allamandola, L. J. 1994, J. Phys. Chem., 98 4243

Hudgins, D. M., Bauschlicher, Jr., C. W., \& Sandford, S. A. 2004, ApJ, 614, 770

Jolibois, F., Klotz, A., Gadéa, F. X., \& Joblin, C. 2005, A\&A, 444, 629

Kerridge, J. F., Chang, S., \& Shipp, R. 1987, Geochim. Cosmochim. Acta, 51, 2527

Klærke, B., Toker, Y., Rahbek, D. B., Hornekær, L., \& Andersen, L. H. 2013, A\&A, 549, A84

Knorke, H., Langer, J., Oomens, J., \& Dopfer, O. 2009, ApJ, 706, L66

Kraemer, K. E., Sloan, G. C., Bernard-Salas, J., et al. 2006, ApJ, 652, L25

Kuck, D. 2002, Int. J. Mass Spectrom., 213, 101

Lee, C., Yang, W., \& Parr, R. G. 1988, Phys. Rev. B, 37, 785

Liddle, A. 2003, An Introduction to Modern Cosmology (New York: John Wiley $\&$ Sons)

Ling, Y., \& Lifshitz, C. 1998, J. Phys. Chem. A, 102, 708

Linsky, J. L., Draine, B. T., Moos, H. W., et al. 2006, ApJ, 647, 1106

Marshall, A. G., Wang, T. C. L., \& Ricca, T. L. 1985, J. Am. Chem. Soc., 107, 7893

McGuire, B. A., Burkhardt, A. M., Kalenskii, S., et al. 2018, Sci, 359, 202

Montillaud, J., Joblin, C., \& Toublanc, D. 2013, A\&A, 552, A15

Oepts, D., van der Meer, A. F. G., \& Van Amersfoort, P. W. 1995, Infrared Phys. Technol., 36, 297

Onaka, T., Mori, T. I., Sakon, I., et al. 2014, ApJ, 780, 114

Oomens, J., Sartakov, B. G., Meijer, G., \& von Helden, G. 2006, Int. J. Mass Spectrom., 254, 1

Peeters, E. 2011, Proc. Int. Astron. Union, 7, 149
Peeters, E., Allamandola, L. J., Bauschlicher, Jr., C. W., et al. 2004, ApJ, 604, 252

Pendleton, Y. J., \& Allamandola, L. J. 2002, ApJS, 138, 75

Piest, J. A., Oomens, J., Bakker, J., Von Helden, G., \& Meijer, G. 2001, Spectrochim. Acta A, 57, 717

Rauls, E., \& Hornekær, L. 2008, ApJ, 679, 531

Reeves, H., Audouze, J., Fowler, W. A., \& Schramm, D. N. 1973, ApJ, 179, 909

Ricca, A., Bauschlicher, C. W., \& Allamandola, L. J. 2011, ApJ, 727, 128

Ricca, A., Bauschlicher, Jr., C. W., Boersma, C., Tielens, A. G. G. M., \& Allamandola, L. J. 2012, ApJ, 754, 75

Rodriguez Castillo, S., Simon, A., \& Joblin, C. 2018, Int. J. of Mass Spectrom., 429,189

Roueff, E., Herbst, E., Lis, D. C., \& Phillips, T. G. 2007, ApJ, 661, L159

Sandford, S., Bernstein, M., \& Dworkin, J. 2001, Meteorit. Planet. Sci., 36, 1117

Sellgren, K., Werner, M. W., Ingalls, J. G., et al. 2010, ApJ, 722, L54

Settle, R. D. F., \& Rizzo, T. R. 1992, J. Chem. Phys., 97, 2823

Spencer, M. K., Hammond, M. R., \& Zare, R. N. 2008, PNAS, 105, 18096

Thrower, J. D., Jørgensen, B., Friis, E. E., et al. 2012, ApJ, 752, 3

Tielens, A. G. G. M. 2008, ARA\&A, 46, 289

Tielens, A. G. G. M. 2013, Rev. Mod. Phys., 85, 1021

Trinquier, G., Simon, A., Rapacioli, M., \& Gadéa, F. X. 2017, Mol. Astrophys., 7,27

Vala, M. Oomens, J., \& Berden, G. 2017, J. Phys. Chem. A, 121, 4606

Valle, J. J., Eyler, J. R., Oomens, J., et al. 2005, Rev. Sci. Instrum., 76, 1 Wakelam, V., Bron, E., Cazaux, S., et al. 2017, Mol. Astrophys., 9, 1

West, B., Rodriguez Castillo, S., Sit, A., et al. 2018, Phys. Chem. Chem. Phys., 20,7195

Whitmore, F. C. 1932, J. Am. Chem. Soc., 54, 3274

Zhao, Y., \& Truhlar, D. G. 2008, Theor. Chem. Acc., 120, 215 


\section{Appendix A: Anthracene}

\section{A.1. Anthracene cation mass spectrum}

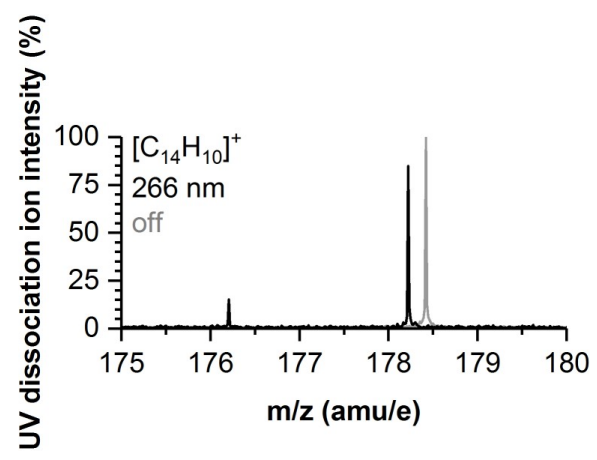

Fig. A.1. Fragmentation mass spectrum of the anthracene cation $\mathrm{C}_{14} \mathrm{H}_{10}^{+}$. The black trace was recorded after exposure to $1 \mathrm{~mJ}$ pulses at $10 \mathrm{~Hz}$ of a $266 \mathrm{~nm}$ (4th harmonic of a Nd:YAG laser) for $3 \mathrm{~s}$, while the gray trace was recorded with the laser off and was given an offset of $0.2 \mathrm{amu}$ for legibility.

Figure A.1 shows fragmentation mass spectra for the radical cation $\mathrm{C}_{14} \mathrm{H}_{10}^{+}$at $m / z=178 \mathrm{amu}$ (gray). After UV irradiation (black), the fragmentation mass spectrum shows one fragment at $m / z=176 \mathrm{amu}$, depicting the loss of two $\mathrm{H}$ atoms as the sole dissociation process from the radical cation, which was also observed by Ekern et al. (1998).

A quantitative interpretation of mass spectra exhibiting sequential $\mathrm{H}$ loss could be complicated by the presence of naturally abundant ${ }^{13} \mathrm{C}$ isotopologs of the $\mathrm{PAH}$ under investigation, amounting to $15.3 \%$ for a molecule with 14 carbons. To ensure the isotopic purity, the mass spectra were made as clean as possible prior to isolation, that is, minimizing the intensity of the cations in the case of protonation, and optimization of the deuteronation vs. the protonation for the deuteronated anthracene. Using unisolated mass spectra, it is possible to make accurate estimates of the isotopic contamination in the precursor peaks for each spectrum. Knowing that the cation only loses two hydrogen atoms, we can discern contributions of the protonated and deuteronated isomers from the contributions of the radical cationic ${ }^{13} \mathrm{C}$ isomers.

\section{A.2. Anthracene band positions}

Table A.1 lists all of the measured band positions of protonated anthracene featured in Figs. 1g,h,i, and compares them with the theoretical band positions of the three different position isomers as calculated using DFT.

Table A.2 lists those measured and calculated for deuteronated anthracene given in Figs. 1j,k,1. Interestingly, the only band not predicted by the 9-isomer is precisely the experimental band at $1360 \mathrm{~cm}^{-1}$. Suitable modes are predicted at $1355 \mathrm{~cm}^{-1}$ for the 1 -isomer (k) and at 1363 for the 2-isomer (1). However, the predicted features of the 1- and 2-isomers around $900 \mathrm{~cm}^{-1}$ are not present in the experiment. Overall, the features are consistent with the 9-isomer.

Table A.3 lists all measured and calculated for protonated, perdeuterated anthracene given in Figs. 1m,n,o. Only calculated frequencies that exhibit enough intensity to allow for comparison with the experimental features are listed.

\section{A.3. Theoretical spectra for additional anthracene isomers}

Figure A.2 displays the six different isotopic isomers that can be formed by a $\left[\mathrm{D}-\mathrm{C}_{14} \mathrm{H}_{10}\right]^{+}$with the aliphatic group at the 9position. These spectra mostly differ in terms of intensity ratios. The only spectrum showing significant changes in band position, is the one where the $\mathrm{D}$ is at the 5 site, opposite the $\mathrm{C}-\mathrm{HH}$ group, which is the most symmetric configuration. This increased symmetry leads to improved resonant enhancement of the in-plane $\mathrm{C}-\mathrm{H}$ bending vibrations, which significantly changes the shape of the spectrum. However, this theoretical spectrum is clearly not in accord with the experimental spectrum. 
S. D. Wiersma et al.: Photolysis-induced scrambling of PAHs as a mechanism for deuterium storage

Table A.1. Band positions in $\mathrm{cm}^{-1}$ of the experimental spectrum of protonated anthracene $\left[\mathrm{H}-\mathrm{C}_{14} \mathrm{H}_{10}\right]^{+}$and the most intense modes of the unconvoluted, theoretical spectra, capped off at $10 \mathrm{~km} \mathrm{~mol}^{-1}$.

\begin{tabular}{|c|c|c|c|c|c|c|c|}
\hline \multicolumn{8}{|c|}{$\left[\mathrm{H}-\mathrm{C}_{14} \mathrm{H}_{10}\right]^{+}$} \\
\hline \multicolumn{2}{|c|}{ Experiment } & \multicolumn{2}{|c|}{ 9-isomer } & \multicolumn{2}{|c|}{ 1-isomer } & \multicolumn{2}{|c|}{ 2-isomer } \\
\hline $\begin{array}{l}\bar{v} \\
\left(\mathrm{~cm}^{-1}\right) \\
\end{array}$ & $\begin{array}{l}I \\
(\mathrm{au}) \\
\end{array}$ & $\begin{array}{l}\bar{v} \\
\left(\mathrm{~cm}^{-1}\right) \\
\end{array}$ & $\begin{array}{l}I \\
\left(\mathrm{~km} \mathrm{~mol}^{-1}\right)\end{array}$ & $\begin{array}{l}\bar{v} \\
\left(\mathrm{~cm}^{-1}\right) \\
\end{array}$ & $\begin{array}{l}I \\
\left(\mathrm{~km} \mathrm{~mol}^{-1}\right)\end{array}$ & $\begin{array}{l}\bar{v} \\
\left(\mathrm{~cm}^{-1}\right)\end{array}$ & $\begin{array}{l}I \\
\left(\mathrm{~km} \mathrm{~mol}^{-1}\right)\end{array}$ \\
\hline \multirow[t]{8}{*}{759} & 0.11 & 755 & 84 & 743 & 41 & 741 & 38 \\
\hline & & & & & & 873 & 34 \\
\hline & & & & & & 886 & 11 \\
\hline & & & & & & 888 & 16 \\
\hline & & & & & & 900 & 15 \\
\hline & & & & 932 & 25 & 911 & 11 \\
\hline & & & & & & 944 & 20 \\
\hline & & 984 & 10 & 1047 & 15 & 1005 & 11 \\
\hline \multirow{2}{*}{1146} & 0.49 & 1146 & 88 & 1163 & 25 & 1155 & 52 \\
\hline & & 1166 & 15 & & & & \\
\hline \multirow[t]{4}{*}{1185} & 0.30 & 1191 & 63 & 1177 & 88 & 1181 & 68 \\
\hline & & & & 1223 & 70 & 1221 & 28 \\
\hline & & 1276 & 20 & 1257 & 12 & 1261 & 13 \\
\hline & & & & & & 1290 & 74 \\
\hline \multirow[t]{7}{*}{1319} & 0.61 & 1312 & 220 & 1324 & 139 & 1309 & 113 \\
\hline & & 1337 & 18 & & & & \\
\hline & & 1347 & 14 & 1335 & 35 & 1333 & 26 \\
\hline & & 1355 & 43 & 1355 & 128 & 1364 & 163 \\
\hline & & & & 1376 & 22 & 1381 & 49 \\
\hline & & 1409 & 65 & 1406 & 13 & 1419 & 12 \\
\hline & & 1438 & 168 & 1432 & 324 & & \\
\hline \multirow[t]{2}{*}{1445} & 1.00 & 1441 & 25 & & & 1441 & 66 \\
\hline & & 1476 & 18 & 1492 & 404 & 1466 & 25 \\
\hline \multirow[t]{3}{*}{1505} & 0.84 & 1501 & 305 & & & 1506 & 32 \\
\hline & & 1535 & 11 & 1521 & 85 & 1523 & 56 \\
\hline & & 1539 & 35 & 1555 & 101 & 1568 & 99 \\
\hline \multirow[t]{2}{*}{1581} & 0.83 & 1578 & 429 & 1590 & 14 & 1592 & 443 \\
\hline & & 1592 & 21 & 1602 & 228 & 1611 & 103 \\
\hline
\end{tabular}

Notes. A scaling factor of 0.9662 has been applied to the calculated spectrum to correct for anharmonicity. The experimental IR intensities are normalized to the highest intensity, while the theoretical IR intensities are the absolute cross sections in $\mathrm{km} \mathrm{mol}^{-1}$.

Table A.2. Band positions in $\mathrm{cm}^{-1}$ of the experimental spectrum of deuteronated anthracene $\left[\mathrm{D}-\mathrm{C}_{14} \mathrm{H}_{10}\right]^{+}$and the most intense modes of the unconvoluted, theoretical spectra, capped off at $10 \mathrm{~km} \mathrm{~mol}^{-1}$.

\begin{tabular}{|c|c|c|c|c|c|c|c|}
\hline \multicolumn{8}{|c|}{$\left[\mathrm{D}-\mathrm{C}_{14} \mathrm{H}_{10}\right]^{+}$} \\
\hline \multicolumn{2}{|c|}{ Experiment } & \multicolumn{2}{|c|}{ 9-isomer } & \multicolumn{2}{|c|}{1 -isomer } & \multicolumn{2}{|c|}{ 2-isomer } \\
\hline $\begin{array}{l}\overline{\bar{v}} \\
\left(\mathrm{~cm}^{-1}\right)\end{array}$ & $\begin{array}{l}I \\
(\mathrm{au})\end{array}$ & $\begin{array}{l}\bar{v} \\
\left(\mathrm{~cm}^{-1}\right)\end{array}$ & $\begin{array}{l}I \\
\left(\mathrm{~km} \mathrm{~mol}^{-1}\right)\end{array}$ & $\begin{array}{l}\bar{v} \\
\left(\mathrm{~cm}^{-1}\right)\end{array}$ & $\begin{array}{l}I \\
\left(\mathrm{~km} \mathrm{~mol}^{-1}\right)\end{array}$ & $\begin{array}{l}\overline{\bar{v}} \\
\left(\mathrm{~cm}^{-1}\right)\end{array}$ & $\begin{array}{l}I \\
\left(\mathrm{~km} \mathrm{~mol}^{-1}\right)\end{array}$ \\
\hline \multirow[t]{6}{*}{758} & 0.07 & 755 & 86 & 743 & 44 & 737 & 13 \\
\hline & & & & & & 742 & 26 \\
\hline & & & & 811 & 14 & 869 & 29 \\
\hline & & & & 828 & 10 & 888 & 20 \\
\hline & & & & 896 & 35 & 913 & 28 \\
\hline & & 984 & 10 & 1048 & 17 & 950 & 14 \\
\hline \multirow[t]{3}{*}{1146} & 0.42 & 1150 & 81 & 1159 & 50 & 1142 & 33 \\
\hline & & 1158 & 12 & 1177 & 95 & 1152 & 137 \\
\hline & & 1167 & 19 & & & 1155 & 46 \\
\hline \multirow[t]{3}{*}{1191} & 0.24 & 1188 & 66 & 1183 & 37 & 1183 & 26 \\
\hline & & 1201 & 25 & 1223 & 54 & 1220 & 29 \\
\hline & & 1276 & 20 & 1265 & 10 & 1261 & 12 \\
\hline \multirow[t]{2}{*}{1315} & 0.61 & 1308 & 178 & 1319 & 19 & 1307 & 15 \\
\hline & & 1333 & 54 & & & & \\
\hline \multirow[t]{4}{*}{1360} & 0.27 & 1337 & 16 & 1355 & 168 & 1363 & 194 \\
\hline & & 1406 & 55 & 1374 & 25 & 1380 & 48 \\
\hline & & & & 1403 & 13 & & \\
\hline & & & & 1424 & 6 & & \\
\hline \multirow{3}{*}{1439} & 1.00 & 1438 & 180 & 1432 & 334 & 1441 & 65 \\
\hline & & 1441 & 24 & & & 1466 & 27 \\
\hline & & 1474 & 25 & & & & \\
\hline \multirow[t]{3}{*}{1499} & 0.85 & 1501 & 305 & 1490 & 434 & 1505 & 42 \\
\hline & & 1534 & 13 & 1520 & 81 & 1523 & 61 \\
\hline & & 1538 & 35 & 1554 & 92 & 1567 & 93 \\
\hline \multirow[t]{2}{*}{1569} & 1.00 & 1577 & 429 & 1590 & 10 & 1592 & 473 \\
\hline & & 1592 & 21 & 1602 & 237 & 1609 & 95 \\
\hline
\end{tabular}

Notes. A scaling factor of 0.9662 has been applied to the calculated spectrum to correct for anharmonicity. The experimental IR intensities are normalized to the highest intensity, while the theoretical IR intensities are the absolute cross sections in $\mathrm{km} \mathrm{mol}^{-1}$. 
Table A.3. Band positions in $\mathrm{cm}^{-1}$ of the experimental spectrum of protonated, perdeuterated anthracene $\left[\mathrm{H}-\mathrm{C}_{14} \mathrm{D}_{10}\right]^{+}$and the most intense modes of the unconvoluted, theoretical spectra, capped off at $10 \mathrm{~km} \mathrm{~mol}^{-1}$.

\begin{tabular}{|c|c|c|c|c|c|c|c|}
\hline \multicolumn{8}{|c|}{$\left[\mathrm{H}-\mathrm{C}_{14} \mathrm{D}_{10}\right]^{+}$} \\
\hline \multicolumn{2}{|c|}{ Experiment } & \multicolumn{2}{|c|}{ 9-isomer } & \multicolumn{2}{|c|}{ 1-isomer } & \multicolumn{2}{|c|}{ 2-isomer } \\
\hline $\begin{array}{l}\bar{v} \\
\left(\mathrm{~cm}^{-1}\right) \\
\end{array}$ & $\begin{array}{l}I \\
(\mathrm{au})\end{array}$ & $\begin{array}{l}\bar{v} \\
\left(\mathrm{~cm}^{-1}\right) \\
\end{array}$ & $\begin{array}{l}I \\
\left(\mathrm{~km} \mathrm{~mol}^{-1}\right)\end{array}$ & $\begin{array}{l}\bar{v} \\
\left(\mathrm{~cm}^{-1}\right) \\
\end{array}$ & $\begin{array}{l}I \\
\left(\mathrm{~km} \mathrm{~mol}^{-1}\right)\end{array}$ & $\begin{array}{l}\bar{v} \\
\left(\mathrm{~cm}^{-1}\right)\end{array}$ & $\begin{array}{l}I \\
\left(\mathrm{~km} \mathrm{~mol}^{-1}\right)\end{array}$ \\
\hline & & 938 & 29 & 932 & 11 & & \\
\hline & & 1139 & 13 & & & 1152 & 134 \\
\hline & & 1197 & 13 & 1179 & 74 & & \\
\hline & & 1206 & 31 & & & & \\
\hline & & & & 1227 & 14 & 1233 & 14 \\
\hline & & 1277 & 67 & & & 1289 & 24 \\
\hline & & 1311 & 70 & & & & \\
\hline 1321 & 0.13 & 1324 & 13 & 1327 & 112 & 1337 & 291 \\
\hline & & 1349 & 28 & 1334 & 39 & 1349 & 33 \\
\hline 1380 & 0.21 & 1371 & 110 & 1402 & 263 & 1391 & 9 \\
\hline & & 1389 & 19 & 1403 & 46 & 1410 & 43 \\
\hline 1450 & 1 & 1451 & 451 & 1452 & 552 & 1473 & 16 \\
\hline & & 1494 & 73 & 1486 & 169 & 1488 & 120 \\
\hline & & 1499 & 27 & 1506 & 74 & 1532 & 11 \\
\hline 1540 & 0.79 & 1540 & 555 & & & 1560 & 524 \\
\hline & & 1559 & 14 & 1575 & 273 & 1577 & 162 \\
\hline
\end{tabular}

Notes. A scaling factor of 0.9662 has been applied to the calculated spectrum to correct for anharmonicity. The experimental IR intensities are normalized to the highest intensity, while the theoretical IR intensities are the absolute cross sections in $\mathrm{km} \mathrm{mol}^{-1}$.

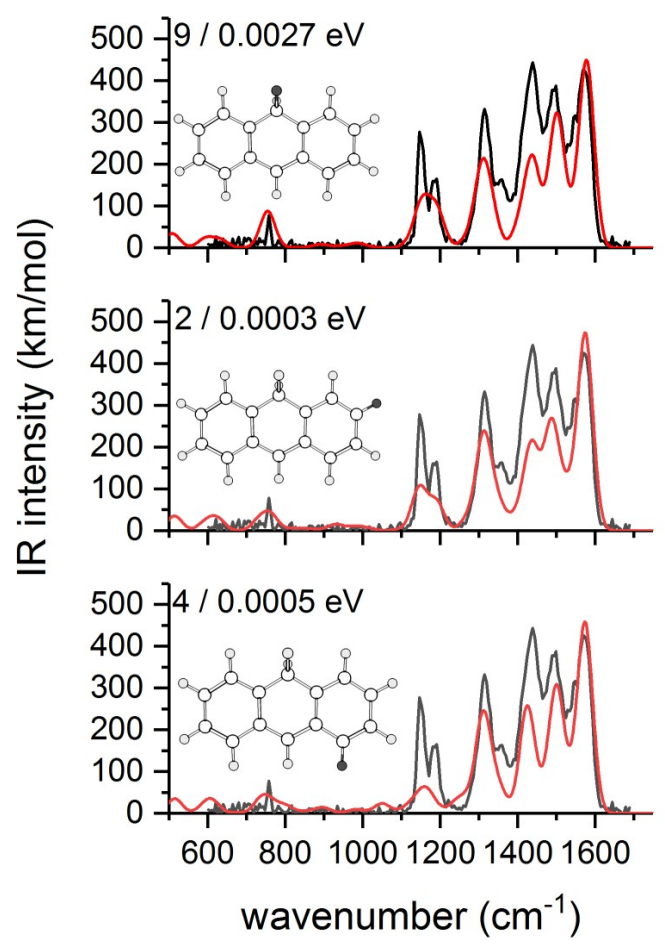

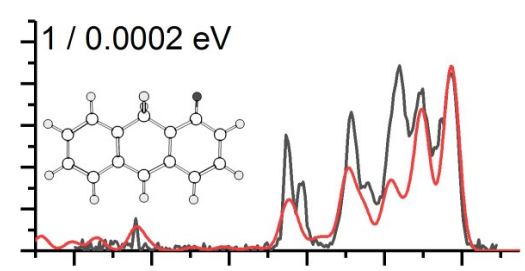
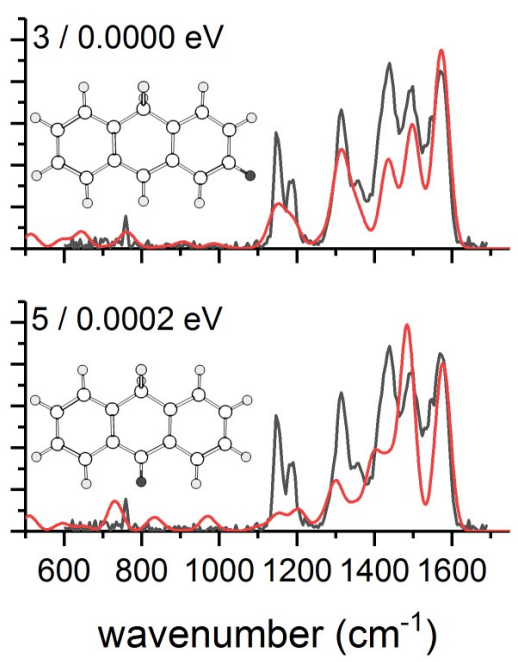

Fig. A.2. Calculations for the six scrambling isomers for the 9-isomer of deuteronated anthracene (red) compared to the FELIX IRMPD spectrum of $\left[\mathrm{D}-\mathrm{C}_{14} \mathrm{H}_{10}\right]^{+}$(black). The shifting $\mathrm{D}$ atom is marked in black on the molecule, and the label in the upper right corner of each panel indicates its position. The energies of each of these isomers is listed in $\mathrm{eV}$ with respect to the global minimum. 
S. D. Wiersma et al.: Photolysis-induced scrambling of PAHs as a mechanism for deuterium storage

\section{Appendix B: Phenanthrene}

\section{B.1. Band positions for phenanthrene}

Table B.1 lists all of the measured bands visible in Figs. 4b-f, and compares them with the calculated band positions of the five different position isomers.

Table B.1. Band positions in $\mathrm{cm}^{-1}$ of the experimental spectrum of protonated, perdeuterated phenanthrene $\left[\mathrm{H}-\mathrm{C}_{14} \mathrm{D}_{10}\right]^{+}$and the most intense modes of the unconvoluted, theoretical spectra, capped off at $10 \mathrm{~km} \mathrm{~mol}^{-1}$.

\begin{tabular}{|c|c|c|c|c|c|c|c|c|c|c|c|}
\hline \multicolumn{12}{|c|}{$\mathrm{H}^{+} \mathrm{C}_{14} \mathrm{D}_{10}$} \\
\hline \multicolumn{2}{|c|}{ Experiment } & \multicolumn{2}{|c|}{ 9-isomer } & \multicolumn{2}{|c|}{ 1-isomer } & \multicolumn{2}{|c|}{ 3-isomer } & \multicolumn{2}{|c|}{ 4-isomer } & \multicolumn{2}{|c|}{ 2-isomer } \\
\hline $\begin{array}{l}\bar{v} \\
\left(\mathrm{~cm}^{-1}\right) \\
\end{array}$ & $\begin{array}{l}I \\
(\mathrm{au})\end{array}$ & $\begin{array}{l}\bar{v} \\
\left(\mathrm{~cm}^{-1}\right)\end{array}$ & $\begin{array}{l}I \\
\left(\mathrm{~km} \mathrm{~mol}^{-1}\right)\end{array}$ & $\begin{array}{l}\bar{v} \\
\left(\mathrm{~cm}^{-1}\right)\end{array}$ & $\begin{array}{l}I \\
\left(\mathrm{~km} \mathrm{~mol}^{-1}\right)\end{array}$ & $\begin{array}{l}\bar{v} \\
\left(\mathrm{~cm}^{-1}\right)\end{array}$ & $\begin{array}{l}I \\
\left(\mathrm{~km} \mathrm{~mol}^{-1}\right)\end{array}$ & $\begin{array}{l}\bar{v} \\
\left(\mathrm{~cm}^{-1}\right)\end{array}$ & $\begin{array}{l}\mathrm{I} \\
\left(\mathrm{km} \mathrm{mol}^{-1}\right)\end{array}$ & $\begin{array}{l}\bar{v} \\
\left(\mathrm{~cm}^{-1}\right)\end{array}$ & $\begin{array}{l}I \\
\left(\mathrm{~km} \mathrm{~mol}^{-1}\right)\end{array}$ \\
\hline & & 1080 & 24 & & & 1108 & 22 & & & & \\
\hline & & 1119 & 15 & & & & & & & & \\
\hline & & 1152 & 74 & 1153 & 81 & 1145 & 128 & 1154 & 29 & 1137 & 120 \\
\hline & & & & 1168 & 23 & & & & & & \\
\hline & & 1298 & 44 & & & 1303 & 60 & & & & \\
\hline & & & & 1314 & 394 & 1308 & 103 & & & 1314 & 83 \\
\hline & & & & 1317 & 22 & & & 1323 & 48 & & \\
\hline 1353 & 1 & 1351 & 284 & 1332 & 165 & 1352 & 125 & 1332 & 187 & 1345 & 31 \\
\hline & & 1367 & 169 & & & 1365 & 55 & & & & \\
\hline & & 1387 & 23 & & & & & 1387 & 46 & 1382 & 182 \\
\hline & & & & & & & & 1398 & 262 & & \\
\hline & & & & & & 1435 & 125 & & & 1402 & 39 \\
\hline 1463 & 0.75 & 1450 & 99 & 1456 & 323 & 1452 & 277 & 1451 & 284 & 1465 & 48 \\
\hline & & & & & & & & & & 1496 & 65 \\
\hline & & & & & & 1520 & 238 & 1483 & 24 & 1532 & 232 \\
\hline & & 1551 & 44 & 1510 & 170 & 1541 & 29 & 1517 & 29 & 1558 & 100 \\
\hline 1565 & 0.59 & 1560 & 287 & 1556 & 54 & 1579 & 115 & 1566 & 134 & 1567 & 140 \\
\hline
\end{tabular}

Notes. A scaling factor of 0.9662 has been applied to the calculated spectrum to correct for anharmonicity. The experimental IR intensities are normalized to the highest intensity, while the theoretical IR intensities are the absolute cross sections in $\mathrm{km} / \mathrm{mol}$. 